\title{
Paper Problem-Based learning (p-PBL) Versus Technology-Enhanced Decision-Based PBL (d-PBL) in the Classroom: Is There an Educational Difference when Using Virtual Patients?
}

\author{
Monika Sobocan $^{1}$ (D) $\cdot$ Neja Turk $^{1} \cdot$ Breda Pecovnik Balon $^{2}$
}

Published online: 9 November 2016

(C) International Association of Medical Science Educators 2016

\section{Introduction}

Problem-based learning (PBL) has long been recognised as an important component of the medical curriculum. Koh (2016) states that the medical education community has not reached a consensus on the characteristics of PBL, which therefore defines it more as a general educational strategy than an educational method [1]. The "traditional" PBL, as most educators understand it, allows students to work on a case in a series of sessions. The problem is progressively revealed to the students through a supervisor (facilitator), who enables students to identify learning objectives and conducts literature research to reach those objectives $[2,3]$. Medical curricula worldwide have integrated PBL as part of the teaching strategy. With the rise of technology-enhanced learning, the thought of upgrading current PBL practices with virtual patients (VPs) has become more tempting. Thus, schools have sought more advanced technological solutions to invigorate their PBL teaching. Reports are currently available regarding the replacement of paper-based PBL (p-PBL) cases with decisionbased PBL (d-PBL), conducted through the creation and use of VPs $[2,4,5]$. In a time when technology is becoming

Monika Sobocan

monika.sobocan@gmail.com

Neja Turk

neja.turk1@gmail.com

Breda Pecovnik Balon

breda.balon@guest.arnes.si

1 Faculty of Medicine, University of Maribor, Taborska ulica 8, 2000 Maribor, Slovenia

2 Faculty of Medicine, Department of Internal Medicine, University of Maribor, Taborska ulica 8, 2000 Maribor, Slovenia increasingly present in the medical education curricula, the question is whether we diminish learning by using technologyenhanced learning tools in PBL sessions.

Our commentary presents the viewpoint regarding the right time to use p-PBL, d-PBL, or PBL with VPs. Subsequently, we discuss the aims of such activities and explore the limits and benefits of technology use in a PBL setting.

\section{Traditional Versus Technology-Enhanced PBL Using VP: Are They the Same?}

The p-PBL model presents students in different stages of their medical education with a problem as an outline for small group work, identification of issues, knowledge revision and acquisition, and situational learning. Students solve a clinical problem in several sessions by using their own knowledge and literature research $[2,3]$. In comparison, d-PBL has no fixed outcome, but leads students with the use of interactive patient scenarios [6] in which they decide on the examination, diagnostics, and treatment of the patient in a specific case. The case unfolds based on the decisions of the students. Students then get immediate feedback and learn from their mistakes [7, 8].

As currently understood, PBL is a way for students to i) identify learning issues, ii) learn how to discuss the treatment of a patient and collaborate in teams, iii) learn how to scaffold their cases, and iv) enhance their self-directed learning [3]. DPBL upgrades the traditional concept of PBL by allowing students to make mistakes and lead patient management in the way they deem fit. This enables them to discuss their mistakes and improve their learning through discussion. The process can be done with computerised decision trees and a basic overhaul of p-PBL or with available commercial products.

VPs are a subtype of commercial d-PBL. Teaching with VPs is meant to focus mainly on the improvement of clinical 
diagnostic skills and patient treatment. This method (VPs) can still have the attributes of traditional PBL, such as working in a small group, learning teamwork, and identifying some knowledge gaps. Mainly, however, the VP focus is on solving the problem rather than on questioning the students' explanation skills. It limits the role of the facilitator (the scripts are pre-written) and focuses students on the goal-solving the clinical problem. This can lead to a more effective, but also narrower, spectre of education.

\section{Approaching the Change from p-PBL to d-PBL with VPs}

Our viewpoint builds upon the published research, when schools transitioned from a p-PBL system to a d-PBL system with VPs. The transition has been done in intermediate medical education with students who already have some $\mathrm{p}-\mathrm{PBL}$ experience $[4,9]$. Those cases were reworked from static PBL cases to d-PBL. The static clinical cases were integrated in a decision tree and then presented to the students [5]. Satisfaction was reported initially when moving to a VPbased model $[5,9]$, but after a few years of execution, as innovation faded, it was found to be less interesting for the students than it had been early in the d-PBL sessions [2].

\section{When Do We Invigorate PBL with VP?}

Whilst it seems easy to assume VPs would be a muchappreciated advancement for PBL, the structure and preprogrammed pathways may limit the educational opportunities for students. For example, in 1993, Dolmans and colleagues explored the learning issues in PBL identified by students and by their instructors [10]. What they found was that the learning issues identified by the parties differed. An overlap of issues and aims was identified only $64 \%$ of the time. This illustrates how p-PBL enables the students to suit the case to their own educational needs [10]. Traditional p-PBL enables students, with the help of their instructors, to suit their own educational needs. These needs might not be the same as identified by VP developers. Rather than following the needs of the students, d-PBL using VPs follows, in most cases, nationally set learning goals [11]. Table 1 depicts, in practical examples, what the possible learning goals could be for the underlying pathology and how they could differ between the PBL teaching tools used (comparing p-PBL and VP PBL).

Learning about patient management from the time symptoms first present until they are treated is a highly appreciated characteristic of VPs in general, but it might be an obstacle too deep, linked learning, especially in the early and intermediate years of medical education. The exploration of issues might be deeper with a p-PBL case than it is with VPs. As shown in a recent reflection on the development of $\mathrm{PBL}, \mathrm{PBL}$ is a starting point for learning [12]. The learning objectives of the case are to anchor basic knowledge and apply it to clinical concepts. In the process, technology-based education can present students with rich clinical problems, structuring knowledge and skill, whilst reducing cognitive load [13]. When the educator identifies needs to move towards more clinical problems and give students more structure for patient care, then it is the time to transfer to d-PBL methods. In the beginning, the technologyenhanced PBL does not need to be a VP PBL, but a hybrid that provides the space to learn broadly, however, that also steers the case according to student decisions. The VP's focus can be a weakness, not a strength, if integrated in the curriculum too early.

Studies show that whilst students are in intermediate clinical education, they show a high understanding of patient evaluation and initial procedure, but they lack understanding
Table 1 Implications of different PBL teaching methods on learning objectives

\begin{tabular}{|c|c|c|}
\hline \multirow{2}{*}{$\begin{array}{l}\text { Underlying pathology } \\
\text { to be explored }\end{array}$} & \multicolumn{2}{|c|}{ Possible learning objectives according to teaching method } \\
\hline & Paper-based PBL (p-PBL; static) & Decision-based PBL (d-PBL) \\
\hline Asthma & $\begin{array}{l}\text { Exploring the concepts of asthma } \\
\text { pathophysiology }\end{array}$ & $\begin{array}{l}\text { Recognising patients with asthma symptoms } \\
\text { as well as initiating appropriate diagnostic } \\
\text { measures and treatments based upon the } \\
\text { clinical presentation }\end{array}$ \\
\hline Heart failure & $\begin{array}{l}\text { Applying theoretical anatomy } \\
\text { knowledge of the heart to the } \\
\text { clinical consequences of } \\
\text { congestive heart failure }\end{array}$ & $\begin{array}{l}\text { Understanding the appropriate immediate } \\
\text { and long-term treatment strategy according } \\
\text { to the disease stage }\end{array}$ \\
\hline Deep vein thrombosis & $\begin{array}{l}\text { Discussing and exploring clotting } \\
\text { disorders leading to deep vein } \\
\text { thrombosis }\end{array}$ & $\begin{array}{l}\text { Exploring the relevance of clinical examination } \\
\text { tests for deep vein thrombosis and the } \\
\text { importance of ultrasound diagnostics }\end{array}$ \\
\hline Glaucoma & $\begin{array}{l}\text { Exploring the impact of diabetes } \\
\text { on the development and } \\
\text { pathophysiology of glaucoma }\end{array}$ & $\begin{array}{l}\text { Discussing the impact of an ophthalmologic } \\
\text { exam for the treatment of glaucoma, } \\
\text { determining what is the relevant information } \\
\text { obtained with the diagnostics }\end{array}$ \\
\hline
\end{tabular}


regarding involving the patient in disease management and education [14]. In building these skills, VPs are superior to traditional PBL and should be used for student teaching. In this way, we exploit the benefits of VPs in the intermediate year without diminishing broad learning through p-PBL. With respect to theoretical learning regarding pathologies and PBL, VPs provide students the opportunity to learn better patient management and about the crucial involvement of stakeholders in decisions. Therefore, we do believe that VPs in intermediate years have an accompanying role with traditional PBL, digital PBL, and teaching of clinical subjects. Edelbring and colleagues [15] tested the integration of the use of VPs in a paediatrics clerkship. The result was that, although VPs were perceived as useful by students, they need to be accompanied and aligned with other educational activities.

In PBL, the VPs role should intensify as students advance in their medical education. In practice, this means medical educators should, based on current evidence, focus on problem-based teaching and increase d-PBL, followed by VP PBL. In the earlier years, a case can be made to use traditional, wide-spectrum PBL. VPs in that phase should be exploited for their unique characteristics, enabling training in clinical or communication skills [8]. However, towards the final years of undergraduate medical education, the focus must shift intensively towards VPs with the aim of standardising the clinical practice of students. In that time, students receive most of their education in clinical wards and need support to make decisions about patient management. This enables us to enhance their clinical clerkships [16]. The various possibilities of medical-knowledge exploration that students receive with $\mathrm{p}$-PBL are a benefit we should not ignore in favour of technology. Therefore, a gradual increase of d-PBL combined with p-PBL sessions is necessary in the undergraduate medical curriculum.

\section{Conclusions}

When considering what strategy to use to best teach students, the question becomes "what is our aim?" When our aim is to give focused, standardised patient-treatment training, then the right choice is to substitute p-PBL sessions with d-PBL using VPs. Whilst VPs are mostly used to achieve improved clinical thinking [17-19], they can also be used for other activities, such as teaching core knowledge, clinical skills, or communication skills, or assessing learner progress [8]. The role of VPs is to be a companion to basic knowledge methods in intermediate education and to take the lead role in strict clinical clerkship education. Our current knowledge indicates that this is the most effective way to organise gathered knowledge and to stimulate its use for clinical, diagnostic thinking [17, 20]. When the student group is beginner or intermediate, the aim should be to still provide $\mathrm{p}$-PBL because it offers room for exploration and even more flexibility. Whilst the disadvantage of having a fixed outcome in p-PBL exists [5], it should not matter much to students with less clinical experience. A mixture of p-PBL, d-PBL, and teaching with VPs can be done instead of abolishing traditional PBL sessions altogether. This allows students to explore their own lack of knowledge more deeply and to fill the appropriate knowledge gaps they may not even know they have.

In 2015, Hortsch pointed out that integrating technology for the sake of modernising the educational process itself may not be the best option [21]. As our knowledge on the effects of VPs grows, we have opened our eyes to the opportunities it provides, but we must not disregard the limitations of this educational method.

\section{Compliance with Ethical Standards}

Sources of funding None to declare.

\section{References}

1. Koh GC-H. Revisiting the "Essentials of problem-based learning". Med Educ. 2016;50:596-9. doi:10.1111/medu.12794.

2. Ellaway RH, Poulton T, Jivram T. Decision PBL: a 4-year retrospective case study of the use of virtual patients in problem-based learning. Med Teach. 2015;37(10):926-34. doi:10.3109/0142159 X.2014.970627.

3. Schmidt HG, Rotgans JI, Yew EHJ. The process of problem-based learning: what works and why. Med Educ. 2011;45:792-806. doi:10.1111/j.1365-2923.2011.04035.x.

4. Poulton T, Ellaway RH, Round J, Jivram T, Kavia S, Hilton S. Exploring the efficacy of replacing linear paper-based patient cases in problem-based learning with dynamic web-based virtual patients: Randomized controlled trial. J Med Internet Res 2014;16. doi:10.2196/jmir.3748.

5. Poulton T, Conradi E, Kavia S, Round J, Hilton S. The replacement of "paper" cases by interactive online virtual patients in problem-based learning. Med Teach. 2009;31:752-8. doi:10.1080/01421590903141082.

6. Kononowicz AA, Zary N, Edelbring S, Corral J, Hege I. Virtual patients-What are we talking about? A framework to classify the meanings of the term in healthcare education. BMC Med Educ. 2015;15:1-7. doi:10.1186/s12909-015-0296-3.

7. Gesundheit N, Brutlag P, Youngblood P, Gunning WT, Zary N, Fors $\mathrm{U}$. The use of virtual patients to assess the clinical skills and reasoning of medical students: initial insights on student acceptance. Med Teach. 2009;31:739-42. doi:10.1080/01421590903126489.

8. Berman NB, Durning SJ, Fischer MR, Huwendiek S, Triola MM. The role for virtual patients in the future of medical education. Acad Med 2016;91(9):1217-22. doi:10.1097/ACM.0000000000001146.

9. McLean M, Brazil V, Johnson P. How we "breathed life" into problem-based learning cases using a mobile application. Med Teach. 2014;36:849-52. doi:10.3109/0142159X.2014.886771.

10. Dolmans D, Gijselaers WH, Schmidt HG, van der Meer Syb B. Problem effectiveness in a course using problem-based learning. Acad Med. 1993;68:207-13. 
11. Berman NB, Fall LH, Chessman AW, Dell MR, Lang VJ, Leong SL, et al. A collaborative model for developing and maintaining virtual patients for medical education. Med Teach. 2011;33:31924. doi:10.3109/0142159X.2011.540268.

12. Servant VFC, Schmidt HG. Revisiting "Foundations of problembased learning: some explanatory notes". Med Educ. 2016;50:698701. doi:10.1111/medu. 12803.

13. Jin J, Bridges SM. Educational technologies in problem-based learning in health sciences education: a systematic review. J Med Internet Res. 2014;16, e251. doi:10.2196/jmir.3240.

14. Klemenc-Ketis Z, Kersnik J. Deficiency areas in decision making in undergraduate medical students. Adv Med Educ Pract. 2014;5:2237. doi:10.2147/AMEP.S64920.

15. Edelbring S, Broström O, Henriksson P, Vassiliou D, Spaak J, Dahlgren LO, et al. Integrating virtual patients into courses: follow-up seminars and perceived benefit. Med Educ. 2012;46: 417-25. doi:10.1111/j.1365-2923.2012.04219.x.
16. Sobocan M, Klemenc-Ketis Z. Enhancing primary care clerkships with virtual patients. Educ Prim Care. 2016. doi:10.1080 /14739879.2016.1207102.

17. Posel N, Mcgee JB, Fleiszer DM. Twelve tips to support the development of clinical reasoning skills using virtual patient cases. Med Teach. 2015;37(9):813-8. doi:10.3109/0142159X.2014.993951.

18. Pinnock R, Spence F, Chung A, Booth R. evPaeds: undergraduate clinical reasoning. Clin Teach. 2012;9:152-7. doi:10.1111/j.1743498X.2011.00523.x.

19. Ellaway R, Topps D, Lee S, Armson H. Virtual patient activity patterns for clinical learning. Clin Teach. 2015;12:267-71.

20. Kleinert R, Heiermann N, Plum PS, Wahba R, Chang D-H, Maus $\mathrm{M}$, et al. Web-based immersive virtual patient simulators: positive effect on clinical reasoning in medical education. J Med Internet Res. 2015;17, e263. doi:10.2196/jmir.5035.

21. Hortsch M. "How we learn May not always be good for us"- do new electronic teaching approaches always result in better learning outcomes? Med Teach. 2015;37:507-9. doi:10.3109/0142159 X.2014.1001341. 